

\section{Das andere Blau}

Zur Poetik einer Farbe im modernen Gedicht

J. B. Metzlersche Verlagsbuchhandlung

Stuttgart 
CIP-Kurztitelaufnahme der Deutschen Bibliothek

Overath, Angelika:

Das andere Blau: zur Poetik e. Farbe im modernen Gedicht/

Angelika Overath.

- Stuttgart: Metzler, 1987.

ISBN 978-3-476-00616-5

DOI 10.1007/978-3-476-03242-3

ISBN 978-3-476-03242-3 (eBook)

C 1987 Springer-Verlag GmbH Deutschland

Ursprünglich erschienen bei J. B. Metzlersche Verlagsbuchhandlung und Carl Ernst Poeschel Verlag GmbH in Stuttgart 1987 
Für Elisabeth und Hans Lothar Overath, meine Eltern 


\section{Inhalt}

Danksagung .................. IX

Einleitung:

Blau - ein philologisches Thema? . . . . . . . . . . 1

I. Blau-Symbolik um $1800 \ldots \ldots \ldots$. . . . . . . 9

1. "Als Farbe eine Energie", Goethe

Eine sinnlich-sittliche Charakteristik . . . . . . . . . . 11

2. "Hier der Rube heitres Blau", Schiller

Eine ästhetische Grenzziehung . . . . . . . . . . . . . 23

3. "Alles blau in meinem Buche «, Novalis

Ein poetisches Fluidum . . . . . . . . . . . . 29

II. Blau-Symbolik um $1900 \ldots \ldots$

A. Blau ist ein Klang . . . . . . . . . . . . . 51

1. Mallarmé, Azur . . . . . . . . . . . . 51

2. Rimbaud, Voyelles . . . . . . . . . . . . . 66

3. George, Blaue Stunde . . . . . . . . . . . . . 77

B. Farbwort und Farbding . . . . . . . . . . . . . . 97

4. Rilke, Blaue Hortensie . . . . . . . . . . . . . . . . 97

III. Das Blau in der Tradition der Moderne . . . . . . . . . 117

A. Blau: Poetische Heimat - poetologisches Wort . . . . . . . 119

1. Trakl, Kindheit . . . . . . . . . . . . . . . . . 119

2. Lasker-Schüler, Mein blaues Klavier . . . . . . . . . . 142

3. Benn, Blaue Stunde . . . . . . . . . . . . . . 159

B. Ein u-topisches Licht . . . . . . . . . . . . . . . . 179

4. Celan, Mandorla . . . . . . . . . . . . . . . . 179

Schluß:

Zur Poetik des Blau . . . . . . . . . . . . . . 195

Anmerkungen . . . . . . . . . . . . . . 198

Bibliographie . . . . . . . . . . . . . . 227 
Die Idee für eine Untersuchung über das Blau in der Literatur geht auf den Sommer 1982 zurück. Im Frühjahr 1983 begann ich, sie als Thema einer Dissertation zu erarbeiten. Im Februar 1986 war der Text abgeschlossen.

Danken möchte ich zunächst meinem Doktorvater Prof. Paul Hoffmann, der sich spontan entschlossen hatte, die Arbeit zu betreuen, und mich - wie all die Jahre meines Studiums hindurch - mit unerschütterlicher Geduld unterstützt hat. Seine Seminare und Vorlesungen waren ungewöhnlich lebendige und anregende Treffpunkte für Studenten, die sich mit der modernen europäischen Lyrik - ihrer UUbersetzbarkeit, den Beziehungen zu Musik und Malerei - beschäftigten; sein Manuskript Der Symbolismus (der erste Teil des Buchs erscheint jetzt) blieb, von Hand zu Hand gereicht, grundlegende Orientierung. Das andere Blau nimmt Impulse eines weiteren noch nicht veröffentlichten Buchs aus der Schule Paul Hoffmanns auf. Manfred Koch arbeitet an einer Untersuchung über die Struktur der Erinnerung in der Lyrik der Jahrhundertwende (Schwerpunkt Hugo von Hofmannsthal). Während meiner Analysen stieß ich immer wieder auf die Verbindung des Blau mit Phänomenen von Erinnerung und Sprachfindung. Die Sensibilisierung auf diese Problematik und die daher rührenden Beobachtungen verdanke ich Gesprächen mit Manfred Koch, der in der Folge zu einem unermüdlichen Kritiker in Fragen des Blau wurde. Angelika Lochmann vom Romanischen Seminar danke ich für ihre Begeisterung über das Thema und die sorgfältige Lektüre des Mallarmé- und Rimbaud-Kapitels, sowie für ihren diplomatischen Beistand in Sachen Korsen und anderer Freibeuter. Dr. Ute Oelmann vom George-Archiv der Landesbibliothek Stuttgart gab mir wertvolle Hinweise zu dem Kapitel über Stefan George. Elsie Koch-Pfitzer hat sich die Mühe gemacht, das Manuskript noch einmal für den Druck durchzusehen.

Besonderer Dank gilt Silvia Elisabeth (*3. Januar 1986), die die Entstehung der Arbeit freundlich begleitete und die deutlichsten Impulse für konzentriertes Arbeiten gab.

Schließlich danke ich der Studienstiftung des deutschen Volkes, die dieses Dissertationsprojekt in jeder Hinsicht großzügig unterstützte. 